\title{
(t)
}

\section{O SUBDESENVOLVIMENTO BRASILEIRO: ALGUMAS CHAVES PARA SUA COMPREENSÃO}

\author{
Brazilian underdevelopment: some keys to its understanding \\ Carlos Roberto Marinho da Costa II \\ https://orcid.org/0000-0003-0517-0589
}

\begin{abstract}
RESUMO
A elucidação das razões do subdesenvolvimento brasileiro, no seio de uma sociedade globalizada e desigual é tarefa complexa que impõe os desafios à compreensão da formação político-econômica nacional, assim como o papel da economia brasileira no desenvolvimento econômico global. O presente artigo tem por objetivo problematizar o debate sobre a categoria subdesenvolvimento no pensamento social brasileiro, bem como construir uma análise das diversas contribuições dadas por autores de escolas teóricas diversas. Para fins de nosso estudo, nos dedicamos mais detidamente ao período compreendido entre a nova republica à redemocratização, com breves incursões sobre o momento atual. $O$ estudo pauta-se por uma pesquisa de revisão bibliográfica, de modo que as reflexões construídas ao longo do artigo foram subsidiadas pelas leituras de Celso Furtado e Francisco Oliveira, bem como autores da Teoria Marxista da Dependência, destacadamente Vânia Bambirra, Rui Mauro Marini, além de Theotônio dos Santos.
\end{abstract}

\section{PALAVRAS-CHAVE}

Subdesenvolvimento. Capitalismo. Dependência.

\section{ABSTRACT}

The elucidation of the reasons for Brazilian underdevelopment within a globalized and unequal society is a complex task that imposes the challenges to the understanding of the national political-economic formation, as well as the role of the Brazilian economy in the global economic development. This article aims to problematize the debate about the underdevelopment category in Brazilian social thought, as well as to construct an analysis of the diverse contributions given by authors of diverse theoretical schools. For the purposes of our study, we dedicate ourselves more closely to the period between the new republic to redemocratization, with brief incursions on the present moment. The study is guided by a bibliographical review research, so that the reflections constructed throughout the article were subsidized by the readings of Celso Furtado and Francisco Oliveira, as well as authors of the Marxist Theory of Dependence, notably Vânia Bambirra, Rui Mauro Marini, besides Theotônio dos Santos.

\section{KEYWORDS}

Underdevelopment. Capitalism. Dependence.

Submetido em: 4/2/2020.

Aceito em: 28/4/2020.

\footnotetext{
${ }^{*}$ Assistente Social. Mestre em Serviço Social. Doutorando em Serviço Social pelo Programa de Pós-graduação em Serviço Social da Universidade Federal de Pernambuco.E-mail: carlosrobertomar@hotmail.com.
}

DOI 10.22422/temporalis.2020v20n39p119-131

(cc)) EY A(s) Autora(s)/O(s) Autor(es). 2019 Acesso Aberto Esta obra está licenciada sob os termos da Licença Creative Commons Atribuição 4.0 Internacional (https://creativecommons.org/licenses/by/4.o/deed.pt_BR), que permite copiar e redistribuir o material em qualquer suporte ou formato, bem como adaptar, transformar e criar a partir deste material para qualquer fim, mesmo que comercial. O licenciante não pode revogar estes direitos desde que você respeite os termos da licença.

Temporalis, Brasília (DF), ano 20, n. 39, p. 119-131, jan./jun. 2020. | ISSN 2238-1856 


\title{
1 INTRODUÇÃO
}

\begin{abstract}
A questão do desenvolvimento sob o sistema de produção capitalista é preocupação sempre atual, pois esse é o principal legado que os defensores deste sistema, acreditam que ele é capaz de promover. Com a expansão do capitalismo aos países periféricos, ocorridos nos marcos do capitalismo em sua fase imperialista, estabeleceu-se uma nova relação entre o centro e a periferia em que se evidenciaram estágios de desenvolvimentos diversos, de modo que os países que não experimentaram a revolução industrial não conseguiam protagonismo no mercado mundial.
\end{abstract}

No Brasil, especificamente, o debate do desenvolvimento é introduzido academicamente nos anos de 1950 e 1960, muito influenciados pela nova configuração geopolítica mundial, a partir das produções da Comissão Econômica para América Latina e Caribe (CEPAL), com destacado papel de Celso Furtado, e posteriormente os fundadores da Teoria Marxista da Dependência (TMD), bem como Francisco Oliveira. O debate se travava sob um contexto em que os rumos do capitalismo autônomo teriam sido truncado pelos golpes militares da década seguinte, e pela intervenção estadunidense em muitos países da América Latina.

O presente artigo tem por objetivo problematizar o debate sobre a categoria subdesenvolvimento no pensamento social brasileiro. No primeiro momento traçamos uma contextualização histórica sobre o debate da economia do desenvolvimento entre alguns clássicos e como isto fundamentou uma primeira aproximação para a apropriação teórica sobre o debate latino-americano, com o surgimento da CEPAL e as contribuições teóricas de Raúl Prebisch. Num segundo momento, apresentamos as análises de Celso Furtado sobre a relação desenvolvimento/subdesenvolvimento, e sua transição teórica dos neoclássicos ao método histórico-estrutural, que possibilitou lançar novas luzes de compreensão sobre o problema. Por fim, na tentativa de traçar um debate mais contemporâneo, apresentamos a título de provocação ao debate, algumas reflexões dos teóricos da TMD e mais detidamente as críticas e concepções de Francisco Oliveira.

\section{CONTEXTUALIZAÇÃO DA ECONOMIA DO DESENVOLVIMENTO}

A emergência do desenvolvimento como preocupação heurística do campo relacionado à ciência econômica remonta ao período da economia clássica, com grande influência da revolução industrial e o surgimento do capitalismo enquanto sistema de produção, estendendo-se até os dias atuais. Desta forma, podemos inferir que o aumento da produtividade do trabalho e suas repercussões na distribuição e utilização do produto social se conformará como núcleo central de preocupação da teoria do desenvolvimento.

Entretanto, não conseguimos mensurar a importância do debate sobre a construção acadêmico-cientifica da categoria subdesenvolvimento, que se localiza na teoria do desenvolvimento, sem antes apresentar o contexto histórico em que se insere esse debate. O período histórico de 1945 a 1973, já foram consagrados na historiografia contemporânea como os anos de ouro do capitalismo (HOBSBAWM, 1995), entretanto seus antecedentes remontam a primeira guerra mundial, pois foi neste marco histórico que se gestou a possibilidade de uma coordenação internacional, por meio de instituições multilaterais (BORJA, 2013), mesmo período em que surgiu a revolução russa, como estratégia de construção de um modelo de desenvolvimento alternativo ao capitalismo. 
A primeira guerra mundial possibilitou a ascensão dos Estados Unidos na condição de centro cíclico principal da economia global, revelando a incapacidade inglesa de retomar a economia sua dominação hegemônica. Como elemento precursor das instituições multilaterais, foi estabelecida a proposta de criação da liga das nações, tendo representado uma primeira tentativa de conquista da hegemonia estadunidense ${ }^{1}$, que foi consolidada apenas após a segunda guerra mundial, com todo aparato institucional por meio de acordos e mediações de aparatos multinacionais. O primeiro movimento em direção as construções das bases hegemônicas foi o tratado de Breton Woods, em 1944, com a reorganização do comércio mundial e o estabelecimento do padrão de moeda internacional baseado no padrão dólar, e lastreado em ouro. A esta iniciativa seguiu-se a criação da Organização das Nações Unidas, em 1946, Fundo Monetário Internacional (FMI), Banco Internacional para a Reconstrução e o Desenvolvimento (BIRD, parte integrante do Banco Mundial), Acordo Geral sobre Tarifas e Comércio (GATT), Organização do Tratado do Atlântico Norte (OTAN), dentre outros.

Outro elemento desencadeador no protagonismo americano em meio a nova geopolítica global, foi sem sombra de dúvidas, a criação do plano Marshall, ou plano para recuperação europeia, coordenado pelos Estados Unidos. Numa outra direção -como o plano Marshall não atendia aos novos países independentes, que foram beneficiados com a descolonização- foram criadas comissões no interior da ONU, como estratégia de assessorar e fomentar o desenvolvimento da América Latina, África e Ásia, além da Europa. Na avaliação de Borja (2013) a comissão mais proeminente foi sem sombra de dúvidas a Comissão Econômica para a América Latina (CEPAL), criada em 1948.

Com o período pós-guerra a economia do desenvolvimento ganha centralidade no debate do desenvolvimento capitalista global, com grande afinco dos órgãos multilaterais, que buscavam viabilizar o desenvolvimento capitalista na periferia do capital, diante de uma tentativa de avanço do bloco socialista, em tempos de guerra fria. Neste sentido, não existia uma teoria do desenvolvimento econômico para a periferia do capitalismo, todo conhecimento derivava dos clássicos e neoclássicos que tinham suas produções teóricas inspiradas no modelo Europeu de desenvolvimento, iniciado pelas revoluções burguesas e indústria, diante deste impasse teórico.

Desta forma, num primeiro momento destaca-se a iniciativa de alguns teóricos em promover o retorno a economia clássica e tentar a conformação deste modelo junto a outras construções teóricas neoclássicas, a exemplo de novas reflexões sobre a lei de Say, como chave de compreensão do processo de produção da economia, tratamento de produção de bens fundamentais para a manutenção do trabalhador e como elemento de elevação dos salários, na relação deste com a taxa de lucro, bem como tantos outros elementos definidores da economia. De forma breve, iremos discorrer sobre alguns autores, que empreenderam inicialmente esforços na tentativa de atualização dos debates presentes na economia clássica e neoclássica, como transição para uma economia do desenvolvimento latino-americano.

\footnotetext{
${ }^{1}$ Ficou conhecida também como a sociedade das nações, tinha como objetivo o estabelecimento de um acordo de paz, sua ultima reunião ocorreu em abril e 1942, quatro anos depois surge a ONU, com funções e articulações semelhantes (HOBSBAWM, 1995).
}

Temporalis, Brasília (DF), ano 20, n. 39, p. 119-131, jan./jun. 2020. | ISSN 2238-1856 
Como um dos primeiros trabalhos acadêmicos que discorre especificamente sobre o tema do desenvolvimento Paul Rosenstein Rodan, em 1943, apontava os Problemas de Industrialização da Europa Oriental e Sul oriental ${ }^{2}$ com sua teoria do big push ( grande impulso) que sustentava que para o desenvolvimento da economia local, seria necessário um grande investimento econômico para que houvesse a superação da inercia econômica para um campo de maior desenvolvimento econômico. Em suas notas sobre o grande impulso o autor apresenta a impossibilidade da construção de um ambiente autossustentado a partir de um crescimento gradual, pois o mercado interno inviabilizaria tal iniciativa, sendo esta uma das características das economias subdesenvolvidas. Conforme Borja: “Desde 1943, Rosenstein-Rodan já propunha políticas de desenvolvimento para as áreas subdesenvolvidas da Europa, notadamente as áreas onde a instabilidade política e a disputa ideológica entre os países capitalistas e socialistas eram mais intensas" (BORJA, 2013, p.134).

Destaca-se ainda Ragnar Nurkse (1969) e a teoria do Crescimento Equilibrado, Arthur Lewis (1969) e a tese da Oferta Ilimitada de Mão-de-obra e Walt Whitman Rostow e as Etapas do Crescimento, além de Raúl Prebisch e o sistema centro-periferia, este último, reconhecido como o maior economista latino-americano do século XX. Prebisch ingressou na CEPAL em 1949, tendo contribuído, sobremaneira, para a construção da teoria do subdesenvolvimento latino-americano. Tendo o subdesenvolvimento como sua matéria de pesquisa, apresentou as particularidades da periferia que concentrava seu desenvolvimento econômico no modelo agrário-exportador, com distinções do centro capitalista altamente industrializado, avançando para a $3^{\text {a }}$ revolução industrial.

Na ocasião da criação da CEPAL, em 1948, era previsto uma atuação inicial de 3 anos, passado este período, o órgão passaria por uma avaliação para mensurar sua eficácia. Segundo Furtado (1997), na conferência do México, em 1951, a delegação dos EUA mobilizou todas as forças no sentido de encerrar os trabalhos da Cepal e foi o apoio decidido do governo brasileiro, na presidência de Getúlio Vargas, que conseguiu sustentála. A influência teórica de Prebisch ao estudo do desenvolvimento no Brasil se estendeu de 1940 a 1970 com a tradução de muitos dos seus textos por Celso Furtado, que tiveram muita repercussão no Brasil, abrindo espaço para diálogos com dirigentes da FIESP e CNI. Na década de 1970, Prebisch aprofundou suas reflexões teóricas, com críticas suntuosas ao sistema capitalista em artigos da revista da CEPAL, que foi criada e dirigida por ele em 1976 (OLIVEIRA, 2013). Com o acesso a este canal de comunicação acadêmica, o autor propunha uma estrutura síntese entre o liberalismo e socialismo, preservando á máxima do livre mercado tal cara aos pensadores liberais, mas adotando o uso social do excedente econômico 3 .

Assim, reconhece-se a influência de Prebisch na construção da categoria subdesenvolvimento na América Latina e particularmente no Brasil, tendo influenciado muito o pensamento de Celso Furtado. Sobres a relação entre esses dois pensadores, Oliveira (2013) defende que Prebisch amais alcançou a amplitude de Furtado enquanto cientista social, tendo seus esforços teóricos permanecido restrito à ciência econômica.

\footnotetext{
${ }^{2}$ Este artigo foi reeditado na coletânea A Economia do Subdesenvolvimento, organizada por Agarwala e Singh, cuja edição nos EUA data de 1958 e a edição brasileira de 1969.
} 


\title{
3 A ORIGEM DO SUBDESENVOLVIMENTO BRASILEIRO: A CONCEPÇÃO FURTADIANA
}

"[...] uma das maiores falhas da teoria econômica geral, quando contemplada da periferia, é o seu falso sentido de universalidade." (PREBISCH, 2011, p.149,)

O surgimento de um núcleo de produção industrial capitalista na Europa no século XVIII,acarretou ruptura na economia mundial da época, passando a condicionar quase todos os continentes. O processo de expansão capitalista é compreendido pelo pensamento furtadiano em três movimentos, sendo o primeiro movimento no interior da própria Europa ocidental, com a ampliação do processo de industrialização que rompeu as barreiras territoriais da Inglaterra alcançando outros países; o segundo movimento foi a ampliação da economia industrial europeia a outros continentes, no caso para a Austrália e o oeste norte-americano, por fim a terceira linha de expansão, momento em que a expansão capitalista alcançou regiões já ocupadas, algumas delas com povoamento já consolidado, mas todas com uma realidade em comum: a presença de sistemas econômicos pré-capitalistas, dentre as quais, o Brasil FURTADO, 2016).

\begin{abstract}
Nesse ponto a teoria do desenvolvimento tem que baixar ao plano histórico [...]. É nesse sentido que falamos de economias desenvolvidas e subdesenvolvidas; de economias autônomas e dependentes etc. Consequentemente, a teoria do desenvolvimento, após haver sido apresentada em termos muito gerais, para adquirir precisão deverá assumir formulações especiais relativas a determinados processos históricos de desenvolvimento (FURTADO, 2016, p. 108).
\end{abstract}

Nesta direção, furtado compreendia que o subdesenvolvimento é um processo histórico autônomo, e não uma simples etapa pela qual necessariamente tenham que passar as economias que já alcançaram um nível de desenvolvimento. Assim, na construção da teoria do desenvolvimento, Celso Furtado, transitou de correntes ortodoxas, para sua própria concepção acerca do processo de desenvolvimento e subdesenvolvimento, este processo de autonomização atinge seu auge em meados da década de 1950 (OLIVEIRA, 2003). Movimento semelhante o autor reproduz, quanto a sua concepção da formação sóciohistórica do Brasil, que paulatinamente vai se distanciando do pensamento de Caio Prado Junior, e vai tomando contornos do método histórico-estrutural ${ }^{4}$, que será a base para seu livro Formação econômica do Brasil (BORJA, 2013).

Desta forma, o método histórico-estrutural surge para compensar o vácuo da produção marxista, que desde Lênin, com o desenvolvimento capitalista na Rússia, rigorosamente um estudo aprofundado de uma economia subdesenvolvida, estagnou e ficou replicando velhas reflexões. Conforme Oliveira (2003) mais tarde vai esclarecer "[...]menos que um método é simultaneamente uma denúncia da falência do método neoclássico, a-histórico, então soberano na análise econômica, e um reconhecimento e necessidade de historicizála" (OLIVEIRA, 2003, p. 12).

No supracitado momento teórico de maior maturidade intelectual, em meados dos anos 1950, Furtado se dedica a construção de elementos da teoria do subdesenvolvimento. $O$ que no primeiro momento era compreendido enquanto como um caso especial do desenvolvimento, o subdesenvolvimento passa a ser tratado teoricamente como uma

${ }^{4} \mathrm{O}$ método de análise histórico-estrutural, leva em consideração todas essas peculiaridades de formação de nosso continente, assim em síntese é a operacionalização da máxima: soluções brasileiras, para os problemas brasileiros.

Temporalis, Brasília (DF), ano 20, n. 39, p. 119-131, jan./jun. 2020. | ISSN 2238-1856 
trajetória distinta do processo de desenvolvimento europeu, a semelhança de outras formas históricas já muito bem elaboradas teoricamente, a exemplo da revolução passiva Gramsciana, ou mesmo a via prussiana, que buscam expressar trajetórias de desenvolvimento de países que não experimentaram as revoluções burguesas, e , portanto, ingressaram tardiamente no processo de Desenvolvimento econômicocapitalista.

Ao categorizar os processos de ampliação dos processos produtivos entre desenvolvimento e subdesenvolvimento, destaca Oliveira (2003), que Furtado se envolve numa seara weberiana dos tipos ideais, no intuito de construir aproximações sucessivas com realidade concreta, matizando os diversos níveis de subdesenvolvimento, que por sua vez serão definidos pelo processo de formação sócio-histórica e econômica de cada sociedade, bem como o nível de desenvolvimento das estruturas produtivas, que não dependem exclusivamente dos investimentos internos. A tese cepalino-furtadiana da dualidade entre economias subdesenvolvidas e desenvolvidas é distinta da tese do capitalismo desigual e combinada da tradição marxista, mas especificamente de Lênin e Trotsky, pois para Furtado e seus pares, o desenvolvimento capitalista é compreendido como desigual, entretanto não é combinado. O argumento usado pelo teórico do subdesenvolvimento brasileiro é de que os dois setores não possuem articulação entre si: o setor atrasado é apenas um obstáculo ao crescimento do setor moderno (OLIVEIRA, 2013).

No início de 1950, o autor em questão já almejava a construção teórica da categoria subdesenvolvimento, embora partindo de um referencial teórico ainda eclético, Furtado preservava o senso crítico perante as teorias que subsidiavam as reflexões sobre o processo do desenvolvimento, frente á realidade histórica. Abaixo apresentamos alguns comentários tecidos por Furtado numa mesa-redonda5 realizada em 1957, no Rio de Janeiro, que esclarece a sua oposição a teoria ortodoxa do desenvolvimento:

\footnotetext{
Primeiramente, creio que pecaríamos por um excesso de generalização se, de início, não definíssemos o que entendemos por subdesenvolvimento. Creio que esse conceito possui uma dimensão histórica que não se deve perder de vista. Não há economias subdesenvolvidas por si, mas tão-somente em comparação com outras economias contemporâneas. A Inglaterra do século XVII ou a Itália do século XVI não podem ser consideradas economias subdesenvolvidas. O segundo fato que cumpre destacar é o seguinte: o desenvolvimento econômico dos últimos 150 anos, corretamente qualificado de industrialização, é um fenômeno qualitativamente distinto dos processos de desenvolvimento que as economias tipicamente comerciais conheceram. O crescimento de uma economia industrial é, basicamente, um processo endógeno, inseparável do progresso tecnológico, enquanto que as economias comerciais cresciam principalmente por aglutinação, isto é, por expansão horizontal (FURTADO, 2016, p. 87).
}

Nesta fração textual, o autor esclarece a perspectiva histórica do subdesenvolvimento e as distinções entre a economia industrial e comercial, elementos que de alguma forma foram tratados em obras anteriores ao texto "Desenvolvimento e subdesenvolvimento"6. 0 autor retoma a sua tese de que o capitalismo industrial possui um crescimento endógeno sob imperativo do progresso tecnológico, como condição da formação de capital, tese que

${ }^{5}$ A referida Mesa-redonda, tinha em sua composição, dentre outros, Professor Rosenstein-Rodan, com quem Furtado discordou.

${ }^{6}$ Obra escrita em 1958 para o concurso de economia política da Faculdade Nacional de Direito. 
tem origem no Capital de Marx, que prerroga que quanto maior for a composição orgânica do capital, maior sua rentabilidade.

Nesta direção o autor irá esclarecer em sua obra que num primeiro momento o modelo de desenvolvimento industrial inglês, por iniciativa do empresariado, houve um processo de inovação com introdução de novas técnicas de produção reduzindo o custo unitário do produto, com a nova dinâmica na economia e na sociedade o novo sistema de produção ia absorvendo o sistema pré-capitalista, sem a pressão dos altos salários, determinado agora, pelo nível de subsistência, gerando um excedente estrutural de mão-de-obra. Num segundo momento a diferenciação da estrutura produtiva conferiria dinamismo à demanda, com sua diversificação guiando as mudanças na produção, da mesma forma que a absorção dos trabalhadores excedentes implicaria a determinação dos salários pela produtividade do trabalho (FURTADO, 2016).

Neste segundo momento da evolução do sistema capitalista, os empresários se depararam com a redução progressiva da taxa de lucro, fruto de uma relativa ineslasticidade da mãode-obra, e uma mudança na concepção da intervenção estatal o que acarretou o processo de uma singela redistribuição de renda em seu favor, condicionando o capitalismo a sua internacionalização. Furtado identifica três linhas de evolução diferentes: a primeira marca a linha de desenvolvimento dentro da própria Europa; a segunda assinala um deslocamento das fronteiras européias para novas terras ainda desocupadas e com características físicas similares às da Europa; e a terceira se distingue pela expansão da economia industrial européia rumo às terras de antiga colonização onde havia um sistema econômico de base artesanal já instalado.

Em Furtado (2016) é pontuado que a terceira linha de expansão industrial, ao atingir as antigas colônias, depara-se com áreas densamente povoadas, de hábitos e costumes diversos, contando inclusive com sistemas econômicos e de produção diversos, todos com características comum: não capitalistas A relação inicial entre os países industrializados e as colônias se deu num primeiro momento pelo intercâmbio de matérias-primas, primordiais a produção industriais, em alguns casos forma abertas frentes de comércios e em outras ainda pela produção direta de matérias-primas pelo capital europeu.

Contudo, a resultante foi quase sempre a criação de estruturas híbridas, uma parte das quais tendia a comportar-se como um sistema capitalista, a outra, a manter-se dentro da estrutura preexistente. Esse tipo de estrutura sócioeconômica dualista está na origem do fenômeno do subdesenvolvimento contemporâneo. O subdesenvolvimento é, portanto, um processo histórico autônomo, e não uma etapa pela qual tenham, necessariamente, passado as economias que já alcançaram grau superior de desenvolvimento. Para captar a essência do problema das atuais economias subdesenvolvidas necessário se torna levar em conta essa peculiaridade (FURTADO, 1961, p. 180-181).

No pensamento de Prebisch, parte-se da compreensão de que há um problema originalmente nos termos e processos de trocas entre os países de economias desenvolvidas e subdesenvolvidas, de modo que aperfeiçoando o processo de troca, os países periféricos poderiam ser alçados à condição de países desenvolvidos. O pensamento furtadiano transcende esta compreensão, identificado na origem da formação sóciohistórica e econômica dos países latino-americano o processo de conformação do subdesenvolvimento. 
Conforme já refletido, o pensamento do autor em tela apresenta um dualismo categorizado entre países desenvolvidos e subdesenvolvidos, cabe-nos apresentar a visão do autor sobre os condicionantes no persistente processo de subdesenvolvimento brasileiro. Para o autor da existe um processo de desenvolvimento paralelo à primeira fase do desenvolvimento capitalista, na medida em que as economias periféricas promovem sua transição ao processo de inserção na economia global, de modo que o sistema artesanal, pré-capitalista, foi absorvido, entretanto a massa de lucros gerada pela produção no capitalismo subdesenvolvido, não era totalmente integrado ao sistema econômico, uma vez que o capital original investido era de origem estrangeira, de modo que o processo de tomada de decisão era feito nos países centrais (FURTADO, 2008).

Desta forma, nossa economia era induzida e fomentada de fora para dentro, com grande dependência do capitalismo central, dos países desenvolvidos. Assim, a primeira ação do ciclo de desenvolvimento subdesenvolvido é a demanda por manufaturas, para posteriormente, considerando a restrição externa, efetuar-se a substituição. Isso impunha uma trajetória muito distinta do que era vislumbrando no processo de desenvolvimento clássico dos países centrais, em que as dinamização do mercado se dava a partir da oferta, no subdesenvolvimento, a dinamização deriva da oferta (FURTADO, 2016).O modelo de substituição de importações, imposta as economias subdesenvolvidas, não permite que o setor industrial passe a ser o elemento dinâmico central, uma vez que não depende tão somente das inovações promovidas no processo de produção, mas na demanda formada por indução externa, o que preserva e justifica a atualidade do subdesenvolvimento brasileiro, que nos dias de hoje ainda se preserva enquanto economia subdesenvolvida com grande dependência da venda de commodities.

\section{O SUBDESENVOLVIMENTO LATINOAMERICANO: OUTROS OLHARES}

O pensamento furtadiano, foi precursor da teoria do subdesenvolvimento latinoamericano, com grandes contribuições para o pensamento social brasileiro. Por sua condição de teórico precursor, seu pensamento deixa margens a muitas outras reflexões que se seguiram, seja por lacunas encontradas em seu pensamento, seja mesmo pelas novas determinações sócio-históricas que possibilitam novos olhares e consensos teóricos inovadores sobre o tema do subdesenvolvimento. A este respeito destaco duas importantes contribuições construídas no período histórico imediatamente posterior ao maior arsenal de produção teórica de Furtado, ambos localizados no campo teórico marxista, estamos tratando da teoria marxista da dependência (TMD), bem como das reflexões relativamente mais recentes do sociólogo Francisco Oliveira, que em alguma medida apresentam contrapontos a teoria do subdesenvolvimento de Furtado.

A teoria marxista da dependência (TMD) se conforma enquanto uma elaboração teórica desenvolvida por intelectuais no campo marxista, tendo como maiores expositores nacionais Ruy Mauro Marini, Theotônio dos Santos e Vânia Bambirra, tendo como principal objeto de estudo o processo de subdesenvolvimento na periferia do capital, em contraposição as elaborações teóricas convencionais do Partido Comunista, bem como as construções teóricas compostas por Furtado Prebisch e outros, relacionadas em grande medida com a Comissão Econômica para a América Latina e Caribe (CEPAL).

Sob a base teórica marxista não-convencional a TMD deu outro significado ao subdesenvolvimento, em sua relação com a dependência, de modo que o que se coloca 
para a TMD é que a acumulação de capital ocorre na economia dependente ${ }^{7}$, contudo, sob determinadas condições de tal maneira que, para mais desenvolvimento capitalista, mais amplo deve ser o espectro da dependência. Outrossim, a dependência pode mudar sua expressão, sua forma, seu grau, porém preserva-se como traços das formações econômicas subordinadas ao imperialismo, e, portanto, subdesenvolvidas, ou conforme Santos:

[...] a dependência é uma característica intrínseca do sistema socioeconômico dos países subdesenvolvidos [...]. Esta face interna não é, pois, uma consequência unidirecional de fatores externos, mas sim, a sua própria maneira- o modo dependente- de participar desse processo de desenvolvimento da economia capitalista (SANTOS, 1978, p. 49).

A TMD revisita a categoria do subdesenvolvimento, e aprofunda algumas dimensões não abordadas pelos economistas cepalinos, reforça-se que o subdesenvolvimento, para esta teoria, não se configura pela ausência do desenvolvimento, pois compreende-se que desenvolvimento não é um processo uno, nem tampouco categorizável, mas complexo e repleto de particularidades. De modo que o subdesenvolvimento econômico representa os efeitos das relações capitalistas internacionais, que compelem a subordinação das nações menos desenvolvidas, desencadeando o processo de dependência da periferia ao centro.

[...] desenvolvimento e subdesenvolvimento seriam dois fenômenos decorrentes da acumulação mundial de capital, em que o subdesenvolvimento corresponde à contrapartida do desenvolvimento econômico de alguns poucos países. A história do subdesenvolvimento latino-americano é a história do desenvolvimento do sistema capitalista mundial. Seu estudo é indispensável para quem deseje compreender a situação que se enfrenta atualmente este sistema e as perspectivas que se abrem. Inversamente, somente a compreensão segura da evolução e dos mecanismos que caracterizam a economia capitalista mundial proporciona o marco adequado para localizar e analisar a problemática da América Latina (MARINI, 1977, p.3).

A TMD lança assim novas chaves de compreensão do problema do subdesenvolvimento latino-americano, que avança sobre a compreensão anterior, superando em grande medida o dualismo cepalino e compreendendo a subordinação como processo imanente ao sistema capitalista, mas cuja particularidade deriva da formação sócio-histórica dos países em condição de subdesenvolvimento, não existindo, portanto um subdesenvolvimento sui generis. Outro autor de destaque em suas reflexões sobre o processo de subdesenvolvimento brasileiro é o sociólogo e economista Francisco Oliveira, que tem produzido sobre este tema ate os dias atuais e tornou-se crítico do dualismo cepalino, bem como aponta diversas limitações das reflexões de Celso Furtado, tendo dedicado uma obra especifica a este tema ${ }^{8}$.

\footnotetext{
7 Os autores da TMD não compreendem a categoria dependência como dependência externa, mas numa aproximação com os conceitos trotskysta do capitalismo enquanto um sistema de desenvolvimento desigual e combinado, com expressões muito particulares em países de diferentes formações sócio-históricas e econômicas.

8 Oliveira (2003), em A navegação venturosa: ensaios sobre Celso Furtado, bem como na crítica da razão dualista, o autor tece profundas críticas à Furtado, se redimindo do tom dado as críticas no recente texto do Ornitorrinco "[...] embora arroubos do tempo tenham-me inscritos invectivas contra os cepalinos, eu já me penitenciei desses equívocos, a forma tosca de ajudar a introduzir novos elementos na construção da especificidade da forma brasileira do subdesenvolvimento" (OLIVEIRA, 2013, p. 128).
}

Temporalis, Brasília (DF), ano 20, n. 39, p. 119-131, jan./jun. 2020. | ISSN 2238-1856 
Oliveira avança nos marcos da reflexão de Furtado, compreendendo que o subdesenvolvimento brasileiro não se conformou como um acidente de percurso, mas foi um projeto do desenvolvimento capitalista, em sua fase monopólica. Segundo o autor "O termo subdesenvolvimento não é neutro: ele revela, pelo prefixo 'sub', que a formação periférica assim constituída tinha lugar numa divisão internacional do trabalho capitalista, portanto, hierarquizada, sem o que o próprio conceito não faria sentido" (OLIVEIRA, 2013, p. 128).

Dentre os pontos que o autor apresenta avanços em relação a Furtado, se dá na compreensão da agricultura de subsistência para a acumulação interna do capital. Enquanto na perspectiva furtadiana havia uma insistência na tese do setor atraso como obstáculo para o desenvolvimento, Oliveira compreende que o subdesenvolvimento brasileiro não se conforma como um processo de evolução truncada, na verdade há a produção de dependência pela conjunção do lugar ocupado na divisão internacional do trabalho. Deste modo, o autor verifica que em meio ao complexo imbricamento das relações econômicas e geopolíticas capitalistas o Brasil possui particularidades que o impulsionam ao subdesenvolvimento:

Esse conjunto de imbricações entre agricultura de subsistência, sistema bancário, financiamento da acumulação industrial e barateamento da reprodução da força de trabalho nas cidades, constituía o fulcro do processo de expansão capitalista, que havia deixado de ser percebido pela teorização cepalino-furtadiana, em que pese seu elevado teor heurístico. Tive que entrar em forte discordância com as teorias do atraso na agricultura como fator impeditivo, com a do 'inchaço' das cidades como marginalidade, com o da incompatibilidade o salário mínimo com o a acumulação de capital [...] (OLIVEIRA, 2013, p. 130).

Esses elementos subsidiam o autor a um salto teórico que denota grande qualificação às suas reflexões, uma vez que ele propõe que na realidade brasileira, o processo de subdesenvolvimento é produto de uma forma de modernização conservadora, ou de uma revolução produtiva sem revolução burguesa, em último estágio: um processo transformista, com elementos particulares. O autor observa nas formas e expressões do mundo do trabalho, os elementos que conformam o lugar periférico e subdesenvolvido, na medida em que o exército industrial de reservas, e o grande contingente de trabalhadores informais não expressam tão somente o consumo excedente da mão-de-obra, mas uma forma estratégica de rebaixamento dos custos de reprodução da força de trabalho. Desta forma, conclui o autor:

\footnotetext{
O subdesenvolvimento viria a ser, portanto, a forma de exceção permanente do sistema capitalista na sua periferia [...] o subdesenvolvimento finalmente é a exceção sobre os oprimidos: o mutirão é a autoconstrução como exceção da cidade, o trabalho informal como exceção da mercadoria, o patrimonialismo como exceção da concorrência entre capitais, a coerção estatal como exceção da acumulação privada [...] (OLIVEIRA, 2013, p. 131)
}

Sob esta interpretação, podemos refletir que as razões do subdesenvolvimento não são unilaterais, nem endógenas, mas possui estreita relação com teoria da acumulação do capital, mesmo que esta apresente fragilidades nas formas históricas concretas, de modo particular na periferia do capital. Em nosso caso particular, o processo de industrialização foi realizado de modo apartado a qualquer projeto emancipador, ademais, cabe-nos ainda discutir que a burguesia nacional se acovardou no papel de sócia menor da burguesia 
imperialista, e não construiu aproximações programáticas com as classes subordinadas/subalternizadas.

Todos esses elementos que condicionam e conformam nosso particular processo de subdesenvolvimento, levou o autor buscar uma forma de expressar alegoricamente a condição nacional, reduzindo o Brasil à figura do ornitorrinco. A transformação final do Brasil no "ornitorrinco9" se completou sob o paradigma da terceira revolução industrial, com o avanço da mundialização capitalista, o avanço do conhecimento técnico/tecnológico, que promove um (neo) atraso e que reafirma o lugar do Brasil no capitalismo mundial. Neste cenário "[...] o ornitorrinco está condenado a submeter tudo à voragem da financeirização numa espécie de buraco negro [...]” (OLIVEIRA, 2013, p. 150), concluindo o autor em tom quase profético: "[...] o ornitorrinco capitalista é uma acumulação truncada e uma sociedade desigualitária sem remissão" (OLIVEIRA, 2013, p. 150).

Seguindo a reflexão do autor, podemos pensar que o período recente vivenciado pelo Brasil, discutido por alguns pesquisadores como ciclo neodesenvolvimentista, tratou-se, na verdade, de novas agruras do ornitorrinco. De modo que este suposto ciclo neodesenvolvimentista não se constitui enquanto tentativa de se metamorfosear em um processo de desenvolvimento autônomo, considerando o crescimento econômico exitoso entre os anos de 2003 a 2013, mas na verdade o reforço da sua identidade subdesenvolvida, que teve sua expressão máxima no golpe de 2016 e as contrarreformas sociais que dai decorreu.

\section{CONSIDERAÇÕES FINAIS}

Os esforços de teorização sobre o subdesenvolvimento latino-americano, iniciados em 1949, com importantes debates até os dias atuais, evidencia a trajetória subsidiária da produção capitalista na periferia do capital, e, portanto, sua baixa dinâmica econômicoindustrial, como meio de expansão do capitalismo imperialista central. Neste sentido, podemos afirmar que a tese de Trotsky, que apontavam para o processo de produção desigual e combinada do capital, se configura como uma importante base teórica para a compreensão da conformação do nosso subdesenvolvimento.

Foram muitas as contribuições da escola Cepalina, entre os anos de 1949-1970 sobre o tema do subdesenvolvimento, construindo a compreensão da particularidade do subdesenvolvimento latino-americano, para além da tradição europeia da economia clássica e neoclássica. No seguimento deste lastro de discussão, a TMD contribui com o debate das construções e reconstruções da dependência latino-americana, tendo ainda como base a permanente condição de subdesenvolvimento, tecendo um debate direto com os cepalinos "clássicos", seguidos ainda das reflexões profundas de Francisco Oliveira, com muita criatividade e consistência teórica, reconstitui a compreensão do fenômeno em análise sob o marco teórico da economia política.

\footnotetext{
${ }^{9}$ Metáfora utilizada por Oliveira em seu célebre texto “o Ornitorrinco" para expressar a realidade Brasileira que assim como o animal não evolui em sua condição biológica, da mesma forma o Brasil está fadado a preservar sua condição de subdesenvolvimento e dependência.
}

Temporalis, Brasília (DF), ano 20, n. 39, p. 119-131, jan./jun. 2020. | ISSN 2238-1856 
Na cena contemporânea temos os tensionamentos construídos pelo consenso de Washington e os ajustes fiscais que dele decorre, impõem uma forma muito particular de apropriação do fundo público pelo orçamento fiscal, mediante contrarreformas sociais, privatizações, terceirizações, promovendo uma verdadeira pilhagem dos países subdesenvolvidos. Estas medidas são defendidas pelos neocepalinos como a única forma de promover o desenvolvimento, cabendo ao Estado o papel de mediador do mercado, corrigindo falhas para fomentar o investimento externo. Em suma, as propostas mais recentes da CEPAL se concentram no sentido de estabelecer uma rotina gerencial do Estado, com papel de liberalização financeira externa, de modo a canalizar o capital externo para as atividades produtivas, voltadas à exportação.

Assim, construiu-se uma nova agenda de "reforma das reformas" 10 com aprofundamento da redução do papel do Estado e deslocamento de sua atuação como mediador econômico financeiro na promoção do desenvolvimento econômico, favorecendo o mercado de exportações e o capital portador de juros. Este novo ordenamento centro-periferia, que tem nos órgãos multilaterais o ator político estratégico, exerceu papel estratégico na atual crise econômica brasileira, bem como em outros países que ousaram impor uma relativa autonomia ao mercado mundial, a exemplo da Nicarágua e Venezuela.

Neste cenário histórico de tantos tensionamentos político-econômicos sob a ordem do capital, e de imposições de ajustes econômicos e contrarreformas sociais, faz-se necessário compreender a natureza desigual do sistema capitalista, a histórica relação de subordinação e subdesenvolvimento dos países periféricos. Neste sentido, o retorno às obras de Furtado, Oliveira e os teóricos da TMD ainda guardam muitas chaves de compreensão do Brasil contemporâneo, para que possamos concentrar esforços de pesquisa nas determinações atuais desta relação de subordinação e subdesenvolvimento.

\section{REFERÊNCIAS}

BORJA, Bruno. Formação da teoria de subdesenvolvimento de Celso Furtado. Tese (Doutorado em 2013)-Programa de pós-graduação em Economia da Universidade Federal do Rio de Janeiro, Rio de Janeiro, 2013.

FURTADO, Celso. Desenvolvimento e subdesenvolvimento. Rio de Janeiro: Contraponto; Centro Internacional Celso Furtado, 2016.

FURTADO, Celso. Criatividade de dependência na civilização industrial. São Paulo: Companhia das letras, 2008.

FURTADO, Celso. Obra autobiográfica de Celso Furtado. São Paulo: Paz e Terra, 1997.

FURTADO, Celso. Desenvolvimento e Subdesenvolvimento. Rio de Janeiro: Fundo de Cultura, 1961.

HOBSBAWM, Eric. A era dos extremos: O breve século XX. São Paulo: Companhia das letras, 1995.

\footnotetext{
${ }^{10} \mathrm{O}$ termo, embora redundante, tem por intenção introduzir a origem da imposição das politicas de ajuste fiscal na América Latina, via CEPAL e Fundo Monetário Internacional.
}

Temporalis, Brasília (DF), ano 20, n. 39, p. 119-131, jan.jun. 2020. | ISSN 2238-1856 
LEWIS, W. A. O Desenvolvimento Econômico com Oferta llimitada de Mão-de-obra. In: AGARWALA, A.; SINGH, S. (orgs.) A Economia do Subdesenvolvimento. Rio de Janeiro: Forense, [1954] 1969.

MARINI, Ruy Mauro. Subdesenvolvimento e revolução. Florianópolis: Insular, 2017.

NURKSE, R. Alguns Aspectos Internacionais do Desenvolvimento Econômico. In: AGARWALA, A.; SINGH, S. (orgs.). A Economia do Subdesenvolvimento. Rio de Janeiro: Forense, [1953] 1969.

MARINI, Ruy Mauro. Dialéctica de la Dependencia. 3. ed. México: Série Popular Era, 1977.

NURKSE, R. Alguns Aspectos Internacionais do Desenvolvimento Econômico. In: AGARWALA, A.; SINGH, S. (orgs.). A Economia do Subdesenvolvimento. Rio de Janeiro: Forense, [1953] 1969

OLIVEIRA, Francisco. Crítica à razão dualista: o Ornitorrinco. São Paulo: Boitempo, 2013.

OLIVEIRA, Francisco. A navegação venturosa: ensaios sobre Celso Furtado. São Paulo: Boitempo, 2003.

PREBISCH, R. O Desenvolvimento Econômico da América Latina e Alguns de seus Principais Problemas. In: PREBISCH, R. O Manifesto Latino-Americano e Outros Ensaios. Rio de Janeiro: Contraponto e Centro Internacional Celso Furtado, 2011.

PREBISCH, Raul. Capitalismo Periférico: crisis e transformación. México: FCE, 1993.

ROSENSTEIN-RODAN, P. Problemas de Industrialização da Europa Oriental e Sul-Oriental. In: AGARWALA, A.; SINGH, S. (orgs.). A Economia do Subdesenvolvimento. Rio de Janeiro: Forense, [1943] 1969.

ROSTOW, W. W. A Decolagem para o Desenvolvimento Auto-Sustentado. In: AGARWALA, A.; SINGH, S. (orgs.). A Economia do Subdesenvolvimento. Rio de Janeiro: Forense, [1956] 1969.

SANTOS, Theotônio dos. Socialismo e fascismo. Cidade do México: Edicol, 1978.

\section{Carlos Roberto Marinho da Costa II}

Doutorando em Serviço Social- UFPE, possui graduação em Serviço Social pela Universidade Federal de Pernambuco (2008), Especialização em Gestão Ambiental pela Universidade de Pernambuco- UPE (2009), Especialização em Planejamento e Gestão de Recursos Financeiros na Política de Saúde pela FIOCRUZ/IMIP (2011) e mestrado em Serviço Social pela Universidade Federal de Pernambuco (2015, foi professor substituto da UFPE. Integra a diretoria do CRESS- $4^{a}$ Região, na função de tesoureiro, coordenador da comissão de inscrição e coordenação da comissão de formação profissional. 